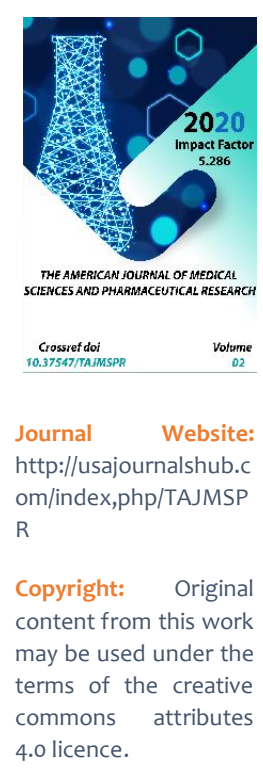

\title{
The Peculiar Case Of Diplopia
}

\section{Dr Anubhav Chauhan}

(M.S Ophthalmology), Medical Officer(Specialist), Deptt. Of Ophthalmology, Shri Lal Bahadur Shastri Government Medical College And Hospital, Nerchowk, Distt. Mandi, Himachal Pradesh, India

\section{Dr Deepak Kumar Sharma}

(M.S Ophthalmology), Assistant Professor, Deptt. Of Ophthalmology, Shri Lal Bahadur Shastri Government Medical College And Hospital, Nerchowk, Distt. Mandi, Himachal Pradesh, India

Dr Pankaj Kumar Thakur

(M.S Ophthalmology), Senior Resident, Deptt. Of Ophthalmology, Shri Lal Bahadur Shastri Government Medical College And Hospital, Nerchowk, Distt. Mandi, Himachal Pradesh, India

Dr Anchit Wapa

(M.S Ophthalmology), Senior Resident, Deptt. Of Ophthalmology, Shri Lal Bahadur Shastri Government Medical College And Hospital, Nerchowk, Distt. Mandi, Himachal Pradesh, India

\section{ABSTRACT}

A nineteen-year-old female presented with a history of binocular diplopia for one week. She had a history of headache, seizures, and memory loss. Magnetic Resonance Imaging (MRI) of brain revealed subependymal astrocytoma as the cause of her symptoms. Our patient was a probable case of tuberous sclerosis complex (TSC). Diplopia was the presenting sign in this case diagnosis.

\section{KEYWORDS}

Intracranial, Tumor, Diplopia

\section{INTRODUCTION}

Intracranial tumours are a leading cause of morbidity and mortality in patients. Clinical features are caused by mass effect, raised intracranial pressure or influence of hormones. Eye signs and symptoms occur as an initial presentation in up to fifty percent of patients diagnosed with primary brain tumours in adults.[1] 


\section{CASE}

A nineteen-year-old female presented with a history of binocular diplopia for one week. There was a history of headache, seizures, and memory loss for the past few years for which she was taking some medicines. There was no other significant perinatal, medical, surgical, family, traumatic or drug abuse history. Ocular examination was carried out and her visual acuity was $6 / 6$ in both the eyes. Her pupillary reactions, ocular movements, colour vision and intraocular pressure were normal bilaterally. Chest, cardiovascular system, skin and abdominal examination was within normal limits. Diplopia charting revealed diplopia in all directions of gaze. Fundus findings revealed bilateral optic disc edema with splinter haemorrhage on both the discs(figure 1b).

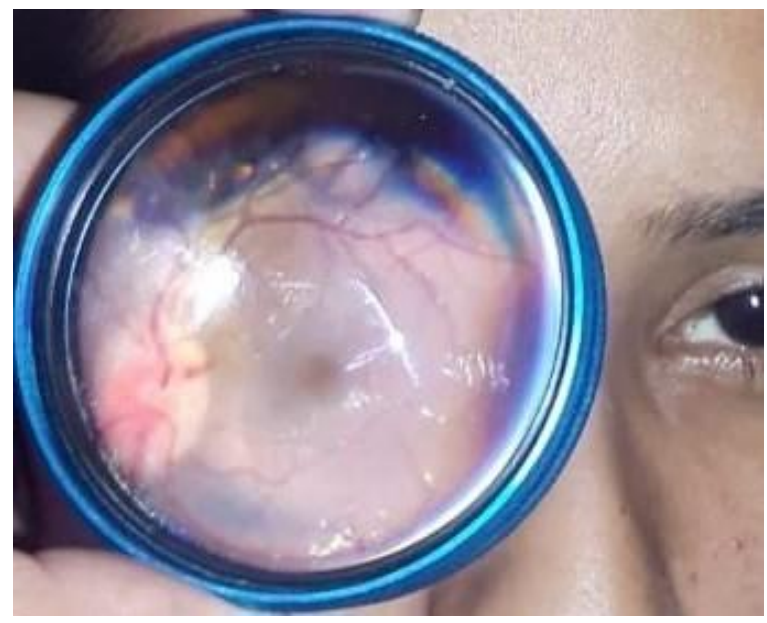

Figure 1a

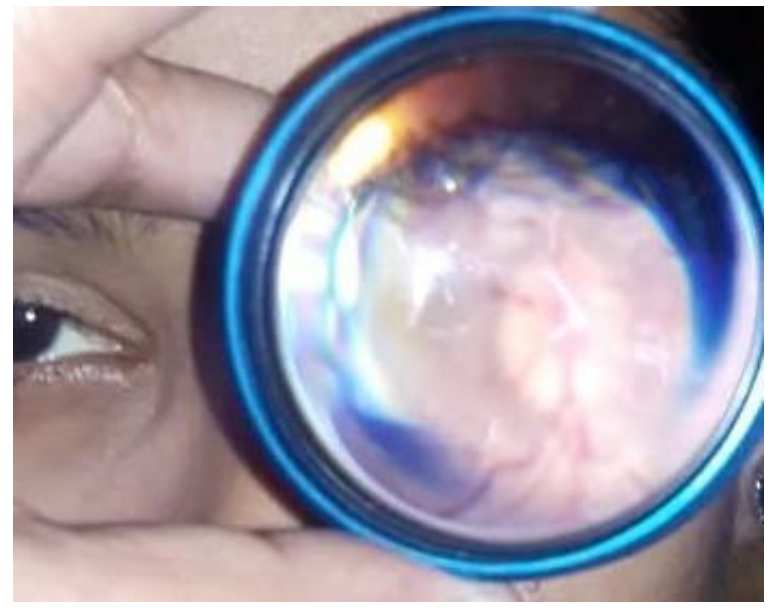

Figure $1 b$

An urgent MRI of the brain(figure 2) was done which revealed "Asymmetric ventricular dilation, left more than the right with with large intensly enhancing intraventricular mass 
left frontal horn near foramen of munro with calcific foci causing mass effect over adjacent right frontal horn and anterior third of third ventricle(Multiple white matter lesions, left frontotemporal lobe with subependymal nodule as described). These features were consistent with probable subependymal astrocytoma". Her laboratory workup was within normal limits. Imaging of the chest, cardiovascular system and gastrointestinal system was not done as the patient was immediately referred to a neurosurgeon. The clinical and radiological findings were consistent with a probable diagnosis of tuberous sclerosis, as it did not fulfill the absolute diagnostic criteria for the disease. One of the causes of the above diagnosis could be the fact that cardiac investigations, chest and abdominal imaging was not done in our case(which could have revealed additional pathologies).

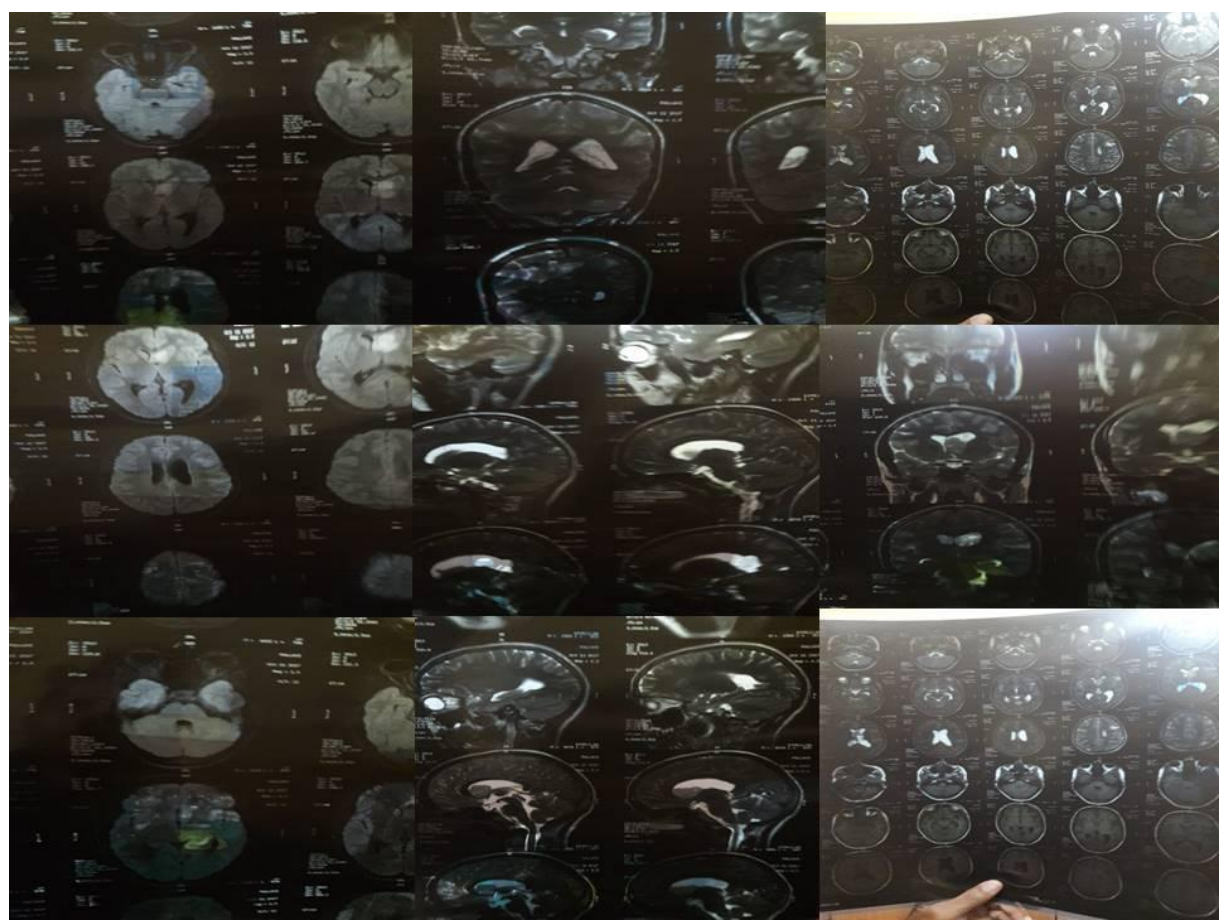

Figure 2

The patient came back to us after a few months and her records revealed that she had undergone ventriculo-peritoneal shunt surgeries and left frontal craniotomy with excision of the mass(which came out as astrocytoma). She was symptomatically better and was on drugs as prescribed by the neurosurgeon.

\section{DISCUSSION}


Ophthalmic signs and symptoms in brain tumors include visual loss, diplopia, nerve palsy, pupillary abnormalities, and optic nerve head defects.[2] TSC is an autosomal dominant diorder which affects nearly all organ systems of the body. It is also known as epiloia or Pringle-Bourneville phacomatosis, and was initially described in the 19 th century by Virchow and Von Reckling-hausen. It affects 1 in every 6,000 to 10,000 individuals and can affect both sexes and all ethnic groups equally. Ocular findings in the form of retinal hamartoma can be present in 30\% to $50 \%$ of patients.[3] According to the new genetic criterion, the identification of the pathogenic mutation in TSC1 or TSC2 DNA is enough to establish the definitive diagnosis of TSC. Clinical criteria to diagnose the disease are as follows. MAJOR CRITERIA: hypopigmented macules ( $\geq 3$, with at least $5 \mathrm{~mm}$ diameter), angiofibromas ( $\geq 3$ ) or fibrous cephalic plaque, ungual fibromas $(\geq 2)$, shagreen patch, multiple retinal hamartomas, cortical dysplasia, subependymal nodules, subependymal giant cell astrocytoma(SEGA), cardiac rhabdomyoma, lymphangioleiomyomatosis, angiomyolipomas $(\geq 2)$.

MINOR CRITERIA::"confetti" lesion, enamel pits (> 3), intraoral fibroma ( $\geq 2)$, retinalhypopigmented macule, multiple renal cysts and nonrenal hamartomas.

Definite diagnosis is eastablished by: Two major features or one major feature with $\geq 2$ minor features.

Probable diagnosisis eastablished by : Either one major feature or $\geq 2$ minor features. [4]
SEGA is a rare tumor that occurs mostly in the wall of the lateral ventricle and foramen of Monro. It is one of the intracranial lesions found in TSC according to the 2012 International Tuberous Sclerosis Complex Consensus Group and is a major criteria. Its incidence varies from $5 \%$ to $14 \%$, and it is mostly encountered before 20 years of age. The clinical features of SEGA are due to hydrocephalus, raised intracranial pressure and seizures. Neuroimaging often reveal a well-circumscribed mass at the foramen of Monro, which frequently exhibits partial calcification or cyst formation.[5] Because of a lack of knowledge of SEGA growth behavior beyond 25 years of age, follow-up MRI may not be needed every 3 years. New onset of symptoms such as headaches, visual complaints, nausea or vomiting, or increase in seizure activity should trigger an earlier scan. The indication for treatment includes new onset of symptoms or radiological evidence of tumor growth.[6] Surgical resection, Gamma Knife radiosurgery or the mechanistic target of rapamycin (mTOR) inhibitors have been used as treatment modalities.[7]

\section{REFERENCES}

1. Tagoe NN, Essuman VA, Fordjuor G, Akpalu J, Bankah P, Ndanu T. NEUROOPHTHALMIC AND CLINICAL CHARACTERISTICS OF BRAIN TUMOURS IN A TERTIARY HOSPITAL IN GHANA.Ghana medical journal 2015; 49(3):181-6.

2. ONAKPOYA OH, KOMOLAFE EO, AKINTOMIDE F, AJITE K, KOMOLAFE MA, ADEOLU AA,et al. OPHTHALMIC 
MANIFESTATIONS IN PATIENTS WITH INTRACRANIAL TUMOURS.African Journal of Neurological Sciences 2009; 28:1.

3. Portocarrero LK, Quental KN, Samorano LP, Oliveira ZN, Rivitti-Machado MC. Tuberous sclerosis complex: review based on new diagnostic criteria. An Bras Dermatol 2018; 93(3):323-31.

4. Northrup H, Krueger DA; International Tuberous Sclerosis Complex Consensus Group. Tuberous sclerosis complex diagnostic criteria update: recommendations of the 2012 International Tuberous Sclerosis Complex Consensus Conference. Pediatr Neurol 2013 ; 49(4): 243-54.

5. Elousrouti LT, Lamchahab $M$, Bougtoub $\mathrm{N}$, Elfatemi H, Chbani L, Harmouch T, et al. Subependymal giant cell astrocytoma (SEGA): a case report and review of the literature.Journal of Medical Case Reports 2016; 10(1): 35 .

6. Roth J, Roach ES, Bartels U, Józwiak S, Koenig MK, Weiner HL. Subependymal Giant Cell Astrocytoma: Diagnosis, Screening, and Treatment. Recommendations From the International Tuberous Sclerosis Complex Consensus Conference 2012.Pediatr Neurol 2013; 49(6): 439-44.
7. Kim JY, Jung TY, Lee KH, Kim SK. Subependymal Giant Cell Astrocytoma Presenting with Tumoral Bleeding: A Case Report. Brain Tumor Res Treat 2017; 5(1):37-41. 